\title{
LA POLISEMIA VERBAL - INTENTO DE EXPLICACIÓN CON LA AYUDA DE LOS VERBOS DE MOVIMIENTO
}

\begin{abstract}
Jansen Silke, La polisemia verbal - intento de explicación con la ayuda de los verbos de movimiento [Verbal polysemy - attempt at explanation by means of verbs of movement]. Studia Romanica Posnaniensia, Adam Mickiewicz University Press, Poznań, vol. XXXI: 2004, pp. 303-310. ISBN 83-232-1353-4, ISSN 0137-2475.

In Spanish, motion verbs are among the verbs that show most polysemic variation. Apart from being used in a literal sense, they also appear in periphrastical expressions that encode temporal and aspectual information. The article shows how the grammatical value of motion verbs is deduced from their lexical meaning, and how both meanings can be distinguished on a formal level due to formal restrictions imposed on certain versions that appear when the grammatical meaning stands in contradiction to some aspects of the lexical meaning.
\end{abstract}

En tanto que característica fundamental de todas las lenguas, la polisemia ha sido objeto de numerosos estudios. Por regla general, la linguística considera como polisemia la capacidad de una entidad léxica de expresar varios sentidos. A diferencia de las palabras homónimas, cuyo significante es idéntico pero que exponen sentidos completamente distintos y por lo tanto representan diferentes unidades léxicas, las acepciones de una palabra polisémica están semánticamente relacionadas y no representan sino variantes de un mismo sentido abstracto. Con esta definición, se plantea el problema de la distinción entre las categorías semánticas de la homonimia y polisemia de un lado y, del otro, entre efectos de sentido polisémicos y sus innumerables realizaciones en el habla. Mientras que en el caso de los substantivos, la delimitación de los efectos de sentido tiene casi como única base el criterio de contigüidad semántica y resulta, por así decirlo, bastante vaga, los verbos exponen numerosas particularidades morfológicas y sintácticas que nos permiten distinguir las diferentes acepciones también en el plano material del lenguaje.

A continuación, nos propondremos definir las diferentes acepciones de algunos verbos de movimiento, apoyándonos en la descripción de las propiedades léxicas y sintácticas que las caracterizan. De esta manera, mostraremos que existen correspondencias sistemáticas entre forma y significado de las construcciones con 
verbos de movimiento, que pueden servir como base formal para distinguir los efectos de sentido de una misma palabra. A partir de las restricciones formales impuestas a ciertas acepciones, propondremos una explicación semántica de la polisemia de los verbos de movimiento.

\section{LAS NOCIONES DE MOVIMIENTO, AGENTIVIDAD Y DIRECCIÓN}

La física define el movimiento como un cambio de lugar en relación con el tiempo. Aunque en la semántica se distinguen diferentes tipos de movimiento ${ }^{1}$, la mayoría de los verbos de movimiento expresa un "desplazamiento del sujeto o del objeto de un lugar A a un lugar B" (Lamiroy, 1991: 24). En los usos prototípicos, el sujeto gramatical cumple con la función semántica de un agente que realiza el movimiento de manera activa e intencional.

Otra noción para caracterizar los verbos de movimiento la constituye la dirección del desplazamiento efectuado por el agente. Por regla general, se hace una distinción bipartida entre los movimientos que parten de un punto y los que tienden hacia un punto (véase Edmundo Ibañez, 1983: 6; Galán Rodríguez 1993, 149)². Esta bipartición se refleja por excelencia en los verbos de movimiento básicos ir y venir, en los cuales se centrará el presente estudio. Como veremos más adelante, la agentividad y la dirección representan dos características fundamentales de los verbos de movimiento, que influyen de manera decisiva en sus propiedades léxicas y sintácticas.

\section{USOS CONCRETOS Y USOS FIGURATIVOS DE LOS VERBOS DE MOVIMIENTO}

Además de sus usos concretos, los verbos de movimiento exponen numerosos sentidos figurativos, sobre todo en el ámbito de los tiempos y aspectos verbales ${ }^{3}$. La polisemia de los verbos de movimiento se manifiesta sobre todo en las perífrasis verbales, especialmente abundantes en el español. Se trata de expresiones compuestas por un verbo principal, exponente del significado léxico de la construcción, que puede aparecer bajo diferentes formas gramaticales (participio, infinitivo,

${ }^{1}$ En su tipología, Galán Rodríguez distingue tres tipos de movimiento: el movimiento propio o activo, en el cual el sujeto realiza el movimiento efectuado y por to tanto actúa como agente, el movimiento no causado por el sujeto o movimiento pasivo, y el movimiento sin cambio de lugar del agente (véase Galán Rodríguez, 1993:148).

${ }^{2}$ A estas dos categorías algunos autores agregan una tercera que abarca los movimientos que pasan a través de un punto (véase Edmundo Ibáñez, 1983: 6; Galán Rodríguez 1993, 149).

${ }^{3}$ Nos encontramos aquí frente a una tendencia presente en un gran número de idiomas, que consiste en concebir el tiempo - una categoría abstracta - a partir de un concepto más concreto y cercano de la realidad de los hablantes que es el del espacio (véase Lamiroy, 1991: 87). 
gerundio), y un verbo auxiliar flexionado, cuya función consiste en determinar el verbo principal en cuanto a diferentes valores temporales o aspectuales. El significado completo de la perífrasis en cierta medida se deduce de los significados de sus constituyentes, pero no corresponde a la suma de ellos: Sólo el verbo principal conserva plenamente su significado léxico, mientras que el verbo auxiliar - en este caso un verbo de movimiento - pierde parte de sus componentes semánticos para convertirse en un elemento gramatical (véase Coseriu, 1996: 126-27; Lamiroy, 1983: 133). De esta forma, en una enunciación como Esta vez no voy a ceder, la idea de desplazamiento de lugar pasa al segundo plano, y la función del verbo ir se reduce al dotar a la acción de ciertos matizes temporales y aspectuales ${ }^{4}$.

Lo que, a pesar de las diferencias, nos permite considerar los diferentes usos de ir como variantes de una misma entidad léxica, son ciertos rasgos esenciales del sentido original que se conservan en la perífrasis. Con la gramaticalización del verbo, desaparece la idea de un desplazamiento físico del agente, pero la expresión de un futuro inmediato ${ }^{5}$ se da precisamente a través de la idea de un desplazamiento abstracto o metafórico, que no se realiza en el espacio, sino en el tiempo. De esta forma, el significado léxico determina el valor gramatical del verbo auxiliar:

La gramaticalización del elemento léxico no es, sin embargo, arbitraria: la fuerza gramatical de un elemento auxiliar corresponderá siempre a su signifiación léxica. Esta significación léxica, es cierto, ha desaparecido, pero se la retiene gramaticalmente: la fuerza gramatical de avoir como "verbo auxiliar" corresponde siempre a la significación de avoir como una unidad léxica; mejor dicho, es siempre la misma significación, sólo que transferida al nivel gramatical y aplicada a una definición gramatical [...] (Coseriu, 1996: 128).

\section{RESTRICCIONES IMPUESTAS A DETERMINADAS ACEPCIONES DE LOS VERBOS DE MOVIMIENTO}

Debido al carácter altamente polisémico de los verbos de movimiento, no siempre es posible precisar si el verbo se usa en sentido concreto o figurativo (p. ej. Voy a comprar leche). Sin embargo, en muchos casos, el contexto léxico o sintáctico ayuda a determinar la interpretación adecuada del verbo. Las características que permiten distinguir los diferentes efectos de sentido se pueden formular como restricciones impuestas a una o varias de sus acepciones posibles, que excluyen que ésta sea interpretada de una forma determinada.

${ }^{4}$ La pérdida del significado léxico original se manifesta muy claramente en casos en los cuales los significados del verbo auxiliar y del verbo principal aparentemente cstán en contradicción: ¿Qué tal vamos en el trabajo? - Pues chico, andamos parados estos días (= estos días no hay trabajo para nadie) (ejemplo tomado de Fente Gómez, Fernández Álvarez, Fejjó, 1997: 41).

${ }^{5}$ Coseriu interpreta la perífrasis con ir como un futuro inmediato, mientras que para Fente Gómez, Fernández Álvarez, Feijoó prevalece el valor aspectual incoativo (véase Coseriu, 1996: 100; Fente Gómez, Fernández Álvarez, Feijoó, 1997: 15). 


\subsection{RESTRICCIONES LÉXICAS}

En el nivel léxico, las restricciones afectan sobre todo a la semántica de los actantes. Como los verbos de movimiento generalmente designan el desplazamiento activo y voluntario de una persona en el espacio, se combinan únicamente con sujetos animados (vgl. Lamiroy, 1983: 204; 1991: 16): Juan va a la tienda a comprar leche. Juan viene a comer. Empleados como auxiliares, ir y venir dejan de exponer esta característica y admiten también sujetos inanimados: Va a llover. Este acontecimiento viene a cambiar mis planes.

La presencia de un sujeto inanimado excluye por lo tanto una interpretación espacial del verbo. Tomando en cuenta la función que los verbos de movimiento adoptan en los perífrasis verbales, esta particularidad no puede extrañar: Al convertirse en elemento gramatical, el verbo pierde parte de su sentido léxico - en este caso, su agentividad -, y con la supresión de la idea de un desplazamiento activo e intencional, desaparece también la selección obligatoria de un sujeto humano o animado (véase Lamiroy 1991: 98) ${ }^{6}$ : Une fois que le verbe atteint le stade d'un auxiliaire de temps, son emploi n'est plus conditionné lexicalement: il fonctionne comme morphème grammatical plutôt que comme lexème (Lamiroy, 1983: 132).

La misma idea de agentividad impide que los verbos de movimiento se combinen con ciertos verbos cuyo sujeto es inactivo: Juan sube a saltar de la torre de saltos. *Juan sube a caerse de la torre de saltos (véase Lamiroy, 1983: 206). Al gramaticalizarse el verbo de movimiento, esta restricción desaparece, y la única manera de interpretar el verbo conjugado es de forma temporal o aspectual: Juan va a caerse de la torre de saltos.

Como la presencia de un verbo con sujeto inactivo excluye una interpretación espacial, no se puede combinar con complementos locativos, y en ausencia de elementos circunstanciales, el verbo de movimiento será interpretado de forma auxiliar: *Juan va a la capital a tener un trabajo mejor pagado. Juan va a tener un trabajo mejor pagado. *Juan vinollegó al banco a tener mucho dinero. Juan vinoflegó a tener mucho dinero.

Lo mismo sucede con los verbos modales, que sólo se combinan con los verbos auxiliares (véase Lamiroy, 1983: 207-8): *Juan vino a la casa a tener que pedir dinero. Juan vino a tener que pedir dinero. ${ }^{*} E v a$ va a los Estados Unidos a poder trabajar. Eva va a poder trabajar.

Mientras que ir y venir exponen una polisemia extramemente rica, en los verbos de movimiento menos frecuentemente usados los usos perifrásticos son mucho más restringidos. El verbo salir, p.ej., adquiere un valor semiperifrástico con algunos verbos de movimiento, entre los cuales los más importantes son correr y volar (véase Fente Gómez, Fernández Álvarez, Feijoó, 1997: 35). El uso de salir

${ }^{6}$ Contrariamente al desplazamiento en el despacio, que puede ser activo o pasivo, el desplazamiento en el tiempo siempre es involuntario. 
«significa que la acción se inicia bruscamente, con connotaciones de sorpresa» (Fente Gómez/Fernández Álvarez/Feijoó, 1997: 35): Si te acercas demasiado, las palomas saldrán volando. ;Venga, sal corriendo ahora mismo!

Sin embargo, la frontera entre perífrasis y simple construcción verbal está tan desdibujada que resulta difícil distinguir ambas acepciones en el plano puramente formal, ya que, con los mismos verbos, salir puede mantener su significado original. En estos casos, la presencia de un elemento circunstancial locativo excluye la interpretación perifrástica: De repente se indignó y salió corriendo de mi oficina. $L a$ paloma se asustó y salió volando del palomar. Sin embargo, con el verbo decir y sinónimos, salir posee pleno valor perifrástico y expresa la idea de sorpresa o irreflexión (véase Fente Gómez, Fernández Álvarez/Feijoó, 1997: 35-36): Después de haber alabado durante horas la obra de Goethe, salió diciendo que no la había leído.

\subsection{RESTRICCIONES TEMPORALES Y MODALES}

En el nivel sintáctico se observan numerosas restricciones que impiden que un verbo auxiliar se utilice en todos los tiempos y modos. Normalmente, los verbos de movimiento automáticamente pierden su valor perifrástico si se usan en los tiempos compuestos, en indefinido o en imperativo. Por ejemplo, la perífrasis ir $a+$ inf. no admite el indefinido, el pretérito perfecto o el pluscuamperfecto (véase Lamiroy 1983: 202; Fente Gómez, Fernández Álvarez, Feijoó, 1997: 15): En frases como $H a$ ido a comprar leche o Fue a comprar leche, es evidente que el hablante se refiere a un desplazamiento concreto en el espacio, mientras que la misma enunciación en el presente o en el imperfecto es ambigua: Vallba a comprar leche.

Como en el caso de las restricciones léxicas, las diferencias sintácticas entre las distintas acepciones resultan del proceso de gramaticalización. Cuando un verbo de movimiento se utiliza como auxiliar, es de la direccionalidad inherente a su significado de la que se deduce el valor aspectual de la perífrasis: $P$. ej., la construcción ir $a+$ inf. llega a expresar un futuro precisamente porque la relación temporal de futuro se concibe metafóricamente como un movimiento que parte del lugar donde se encuentra el hablante y se dirige a otro punto no especificado. Sin embargo, además de las perífrasis, el español dispone de un sistema flexional muy elaborado para expresar matices de tiempo y aspecto. Cada vez que el significado metafórico del verbo de movimiento entra en conflicto con el valor aspectual o temporal inherente a ciertos tiempos verbales, aparecen restricciones temporales para impedir que las informaciones dadas por la forma verbal y el verbo auxiliar sean contradictorias: Por su valor de futuro, la perífrasis ir a +inf. no se puede utilizar en tiempos verbales relacionadas con la idea de perfección.

Restricciones equivalentes se observan en la perífrasis venir $a+$ inf., con valor aproximativo: Juan viene a ganar unos 60.000 euros al año (= gana aproximadamente). En cada uno de sus discursos, el presidente viene a decir lo mismo (= dice 
más o menos lo mismo). Si el verbo aparece en un tiempo compuesto o en indefinido, se pierde el sentido de aproximación (véase Fente Gómez, Femández Álvarez, Feijoó, 1997: 21): Juan vino a ganar 60.000 euros al año. El presidente vino a decir lo mismo que en sus últimos discursos. No obstante, el uso de venir a+ inf. en un tiempo verbal perfectivo no excluye por completo una interpretación figurativa del verbo de movimiento, ya que existe otra perífrasis homónima con el sentido de aproximación a un límite: El premio vino a solucionar sus problemas económicos. Este acontecimiento vino a perturbar la vida tranquila y feliz de Juan. En ambos casos, venir designa el desarrollo de una acción que continúa hasta el momento al que se refiere la enunciación, conservando así la idea de un movimiento metafórico que se dirige hacia el hablante. Sin embargo, en los primeros ejemplos, se enfoca la idea de un acercamiento (= valor aproximativo), mientras que en los últimos, prevalece la idea de la llegada al punto final, lo que le da un matiz perfectivo a la construcción y permite que ésta se use con tiempos verbales relacionados con el aspecto concluido. Como, en el nivel sintáctico, la simple construcción con verbo de movimiento y la perífrasis con valor perfectivo son idénticas, para distinguir las diferentes acepciones hay que recurrir a características léxicas como la presencia de un sujeto animado o inanimado.

La perífrasis venir + gerundio expresa «una acción que ha empezado en un período de tiempo pasado y que se desarrolla gradualmente, con un matiz de insistencia o repetición, hasta el momento al que nos referimos» (Fente Gómez, Fernández Álvarez, Feijoó, 1997: 33): Vengo buscando la solución de este problema. Como la acción designada continúa hasta el momento de la enunciación, esta construcción prácticamente no se utiliza en los tiempos perfectos (véase Fente Gómez, Fernández Álvarez, Feijoó, 1997: 33) ${ }^{7}$.

Las mismas restricciones son válidas en cuanto a la perífrasis ir + participio pasado que expresa una acción comenzada en un momento del pasado y continuando hasta un momento en el futuro que no se especifica: Del libro que hemos escrito, van vendidos 200 ejemplares (= han sido vendidos). El árbitro expulsó al defensa central cuando iban marcados cinco goles (véase Fente Gómez, Fernández Álvarez, Feijoó, 1997: 40). Aquí también, el hecho de que la acción designada continúa más allá del momento de la enunciación impide que el verbo de movimiento se use en un tiempo con valor perfectivo ${ }^{8}$.

${ }^{7}$ En este respecto, existe una estrecha relación entre las perífrasis venir + gerundio y llegar + participio, ya que ambas expresan la idea de la duración de una acción hasta el momento de la enunciación. Sin embargo, debido al uso del participio pasado, la construcción con llegar tiene un carácter pasivo, mientras que el participio presente le otorga un valor activo a la construcción con venir. Como, en el nivel aspectual-temporal, las construcciones son equivalentes, exponen las mismas restricciones en cuanto a los tiempos verbales: «No se puede utilizar esta estructura en los tiempos compuestos, pretérito indefinido ni imperativo" (Fente Gómez, Fernández Álvarez, Feijoó, 1997: 42).

${ }^{8}$ El uso del indefinido resulta perfectamente gramatical, pero expresa otra idea: En la frase $\mathrm{Del}$ libro que escribimos, fueron vendidos 200 ejemplares, prevalece la idea de una acción pasiva y concluída en el pasado. 
Como los verbos de movimiento, en sentido literal, expresan una acción activa y voluntaria del sujeto, naturalmente admiten la forma imperativa. Sin embargo, cuando se utilizan como elementos gramaticales de tiempo o aspecto, el uso del imperativo produce frases agramaticales debido a la relativa inactividad del sujeto: ¡Ven a comer! * ¿Ven a ganar más! ${ }^{9}$ (véase Lamiroy, 1983: 203-204).

\section{CONCLUSIÓN}

En la presente contribución, se ha demostrado que en muchos casos es posible resolver formalmente la ambigüedad entre los verbos de movimiento empleados en su sentido original y en sus respectivos usos figurativos. Muchas de las acepciones de los verbos ir y venir exhiben restricciones que impiden que el verbo sea interpretado de una u otra forma. Esta característica del verbo español se explica por la naturaleza misma de las perífrasis verbales: Empleado como auxiliar, el verbo principal siempre mantiene algunos rasgos de su valor original, mientras que otros se pierden en el proceso de la gramaticalización. Las restricciones se dan cuando los rasgos semánticos del verbo principal están en contradicción con la información que proporciona el contexto léxico o la forma verbal.

En el nivel léxico, son las acepciones concretas las que están sometidas a restricciones: Como su significado léxico es mucho más específico que el valor gramatical de los auxiliares, se pueden dar contradicciones con el significado de otros lexemas de la enunciación, que afectan sobre todo a la naturaleza del sujeto gramatical. Los auxiliares, en cambio, en el proceso de la gramaticalización pierden su agentividad y por lo tanto no exigen un sujeto animado. Sólo los verbos que apenas están por gramaticalizarse como auxiliares (salir) exponen más posibilidades combinatorias en sus usos concretos que en sus usos figurativos.

Contrariamente a las restricciones léxicas, las restricciones temporales aparecen únicamente en los usos figurativos. Ya que, en el proceso de la gramaticalización, los rasgos direccionales del verbo principal se interpretan de manera metafórica y llegan a expresar matices de tiempo y aspecto, pueden entrar en conflicto con los valores aspectuales inherentes a ciertas formas verbales. En estos casos, la lógica del lenguaje actúa en favor de la morfología verbal y no admite que las perífrasis verbales se utilicen en todos los tiempos.

${ }^{9}$ Muy pocos verbos de movimiento siguen utilizándose en imperativo aún cuando se usan como auxiliares: Ponte a trabajar, para de dormir etc. (véase Fente Gómez, Fernández Álvarez, Feijoó, 1997: 96). 


\section{REFERENCIAS BIBLIOGRÁFICAS}

Coseriu, E. (1996), El sistema verbal románico. trad. Carlos Opazo Velásquez. México: Siglo Veintiuno.

Edmundo Ibañez, J. (1983), Estudio de la deixis espacial en los verbos españoles ir y venir con especial consideración del contraste en los verbos de movimiento del francés y del alemán. Hamburg: manuscrito no publicado.

Fente Gómez, R., Fernández Álvarez, J. y Feijoó, L. (1997), Perífrasis verbales. Madrid: Edelsa.

Galán Rodríguez, C. (1993), Aproximación al estudio de los verbos de movimiento en alemán y en español: Movimiento real y empleos figurados. Anuario de Estudios Filológicos 16. 147-157.

Lamiroy, B. (1983), Les verbes de mouvement en français et en espagnol. Amsterdam-Philadelphia: J. Benjamins.

Lamiroy, B. (1991), Léxico y gramática del español. Estructuras verbales de expacio y de tiempo. Barcelona: Anthropos. 